
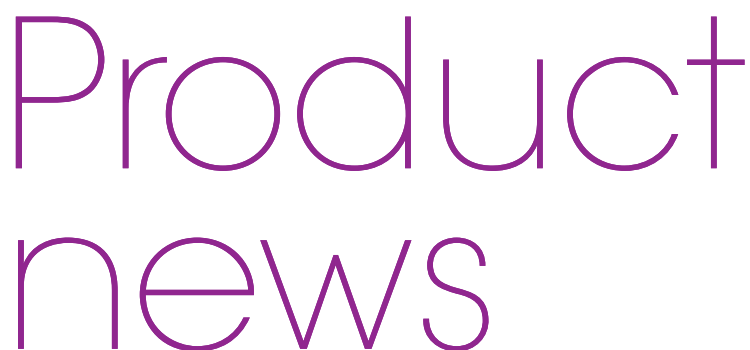

\title{
DENTAL THERAPIST EDUCATES LOCAL COMMUNITY IN KENYA
}

In a recent trip to Msambweni, Kenya undertaken by dental therapist Sarah Childs and Hereford Cathedral School, Curaprox was able to help the cause by donating over 100 CS 5460 manual toothbrushes.

During the ten-day trip Sarah visited a local school, an orphanage and a children's home to provide oral health education. She also provided bespoke advice to smaller groups of people at the local community centre including adolescents, adults and a mother and baby group.

To assist with the learning Sarah handed out goody bags containing a toothbrush, interdental brushes and leaflets, and used fun, educational props such as large teeth and a giant toothbrush. In total, Sarah handed out 1,000 manual toothbrushes, obtained through a combination of fundraising and a donation from Curaprox.

The ultra-soft but highly effective CS 5460 toothbrushes are ideal tools for achieving excellent oral health outcomes.

Sarah said: 'All in all, the trip was very positive, and I'm extremely happy that I was able to educate the community on a complete oral healthcare regime.'

To find out more about CS 5460 toothbrushes, contact Curaprox on 01480 862084, email info@curaprox. co.uk or visit www.curaprox.co.uk.

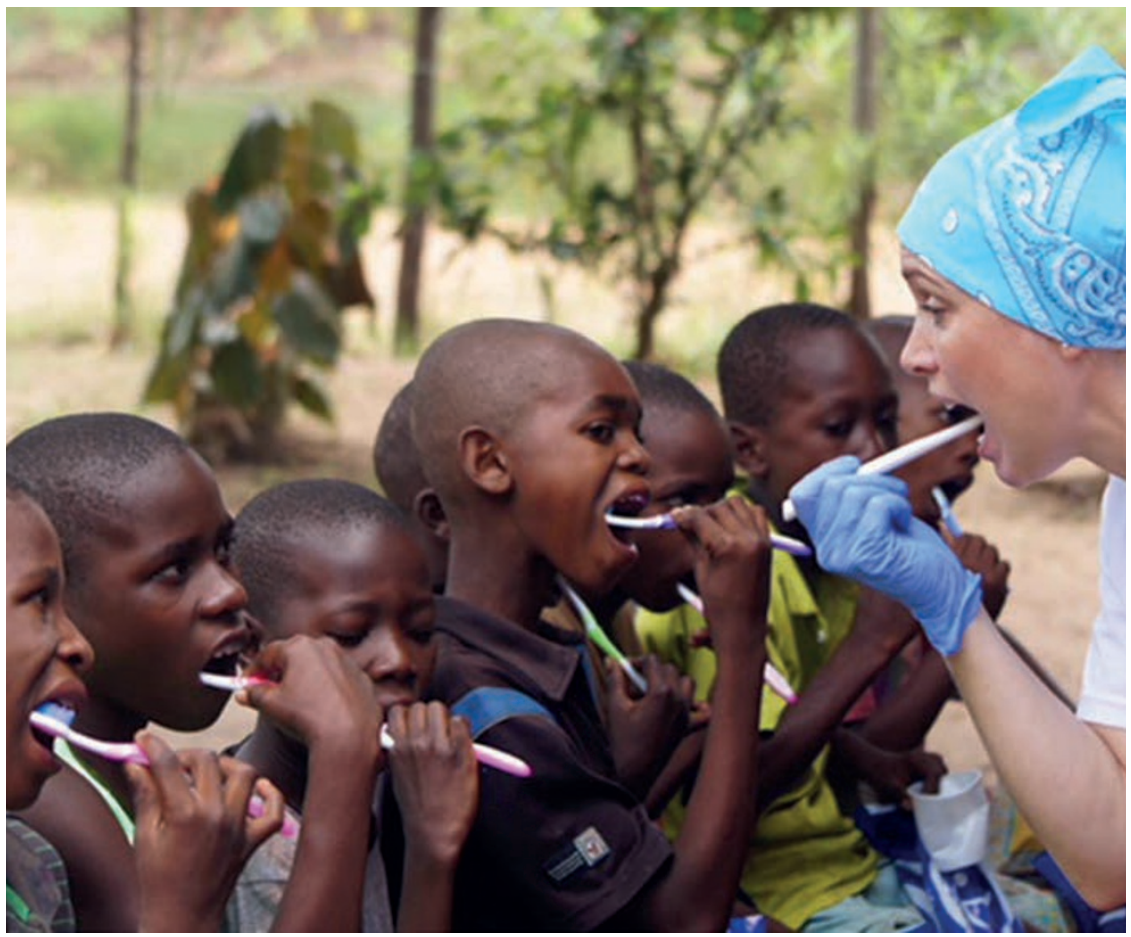

PREMIUM-QUALITY MOUTHWASH

Newly launched to the UK market is WASH \& PREVENT, a premium-quality mouthwash from TANDEX.

WASH \& PREVENT is available in two varieties. One contains fluoride and chlorhexidine to give it an antibacterial effect; the other has added zinc to relieve bad breath

Whichever you choose to recommend, WASH \& PREVENT will offer ideal protection against plaque and caries and will strengthen the enamel too. Pleasant to use, and with a refreshing peppermint flavour WASH \& PREVENT is alcohol free.

WASH \& PREVENT complements the range of outstanding oral care products in the TANDEX range. TANDEX is a Danish company that, since 1931, has been at the forefront of the development and production of preventive oral care tools and adjuncts. These include brushes, interdental brushes, PREVENT GEL and now the WASH \& PREVENT mouthwashes.

Dentists who already know the benefits of TANDEX praise the high functionality and quality of the products. Patient compliance will be high as every element of the range is user friendly and will give great results with regular application.

Give WASH \& PREVENT a try today - and contact TANDEX to find out how its products can make a big difference for your patients.

Visit www.tandex.dk.
MUNDSKYI

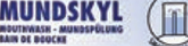

WASHCPREVENT

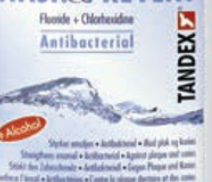

